\title{
Attention Deficit/Hyperactivity Disorder (ADHD) Is Associated With Altered Heart Rate Asymmetry
}

\author{
I. TONHAJZEROVÁ ${ }^{1}$, I. ONDREJKA ${ }^{2}$, I. FARSKÝ ${ }^{2,3}$, Z. VIŠŇOVCOVÁ ${ }^{1}$, M. MEŠŤANÍK ${ }^{1}$, \\ M. JAVORKA ${ }^{1}$, A. JURKO Jr. ${ }^{4}$, A. ČALKOVSKÁ ${ }^{1}$
}

${ }^{1}$ Department of Physiology, Jessenius Faculty of Medicine in Martin, Comenius University in Bratislava, Martin, Slovakia, ${ }^{2}$ Psychiatric Clinic, Jessenius Faculty of Medicine in Martin, Comenius University in Bratislava, Martin, Slovakia, ${ }^{3}$ Department of Nursing, Jessenius Faculty of Medicine in Martin, Comenius University in Bratislava, Martin, Slovakia, ${ }^{4}$ Paediatric Cardiology, Martin, Slovakia

Received March 13, 2014

Accepted August 18, 2014

\begin{abstract}
Summary
Attention deficit/hyperactivity disorder (ADHD) is associated with complex neurocardiac integrity. We aimed to study heart rate time asymmetry as a nonlinear qualitative feature of heart rate variability indicating complexity of cardiac autonomic control at rest and in response to physiological stress (orthostasis) in children suffering from ADHD. Twenty boys with ADHD and 20 healthy age-matched boys at the age of 8 to 12 years were examined. The continuous ECG was recorded in a supine position and during postural change from lying to standing (orthostasis). Time irreversibility indices - Porta's (P\%), Guzik's (G\%) and Ehlers' $^{\prime}(E)$ - were evaluated. Our analysis showed significantly reduced heart rate asymmetry indices at rest (P\%: $49.8 \%$ vs. $52.2 \%$; G\%: $50.2 \%$ vs. $53.2 \%$; $\mathrm{p}<0.02$ ), and in response to orthostatic load (P\%: $52.4 \%$ vs. $54.5 \%$, G\%: $52.3 \%$ vs. $54.5 \%$; $<0.05)$ associated with tachycardia in ADHD children compared to controls. Concluding, our study firstly revealed the altered heart rate asymmetry pattern in children suffering from $\mathrm{ADHD}$ at rest as well as in response to posture change from lying to standing (orthostasis). These findings might reflect an abnormal complex cardiac regulatory system as a potential mechanism leading to later cardiac adverse outcomes in ADHD.
\end{abstract}

\section{Key words}

ADHD • Heart rate asymmetry • Heart rate variability • Cardiac autonomic regulation $\bullet$ Nonlinear analysis

\section{Corresponding author}

I. Tonhajzerova, Department of Physiology, Jessenius Faculty of Medicine in Martin, Comenius University in Bratislava, Mala
Hora 4, 03601 Martin, Slovak Republic.

E-mail: tonhajzerova@jfmed.uniba.sk

\section{Introduction}

The autonomic nervous system (ANS) plays a crucial role in a wide range of mental disorders. Normally, the activities of the sympathetic and parasympathetic branches of the ANS are in dynamic balance and its proper functioning at rest as well as in response to various internal/external stimuli is important for organism flexibility, adaptability and health. In contrast, the autonomic imbalance, in which one branch of the autonomic nervous system dominates over the other, is associated with a lack of dynamic flexibility and health. This state is common to a broad range of maladaptive conditions and it is associated with the increased risk of cardiovascular adverse outcomes (Friedman 2007, Porges 2007, Thayer and Sternberg 2006).

Attention-deficit/hyperactivity disorder (ADHD) is a neurodevelopmental disorder from externalizing mental disorders characterized by distractibility, deficient emotional self-regulation, hyperactivity, impulsive behaviors and inattention (Furman 2005). While it is generally assumed that autonomic regulation is impaired during ADHD, the information pertaining to this dysregulation is limited. However, recent study referred to different autonomic functioning in ADHD: children with ADHD and low prosocial behavior displayed 
blunted parasympathetic and sympathetic activity (i.e. hypoarousal), and children with ADHD and age-typical prosocial behavior showed elevated sympathetic activity indicating high arousal (Musser et al. 2013). The state "hyperarousal" in ADHD indexed by tachycardia was found also in other studies (Tonhajzerova et al. 2009, Imeraj et al. 2011). In contrast, other disorders from externalizing spectrum, such as conduct disorders, aggressive behavior or delinquency, are associated with impaired autonomic functioning characterized by sympathetic and parasympathetic underactivity in accordance with "hypoarousal" theory (Beauchaine 2001, Beauchaine et al. 2007, 2013, Crowell et al. 2006). It seems that the findings of reduced ANS activity in externalizing psychopathology may not blindly be generalized to pure ADHD without comorbidities. This question is still unresolved.

From this context, it is assumed that ADHD is associated with autonomic nervous system dysfunction, and cardiac function is extremely sensitive to autonomic regulatory outputs in the bidirectional "brain-heart" communication (Beauchaine 2001). Thus, an extensive research has been directed to identify the pathway by which this neurocardiac control is achieved (Friedman 2007, Thayer and Lane 2009). Central autonomic network (CAN), as described by Benarroch (1993), represents a highly integrated neural system through which the brain controls visceromotor, neuroendocrine and behavioral responses critical for goal directed and adaptive behavior. The primary output of the CAN mediated by the interplay of sympathetic and parasympathetic neurons innervating sinoatrial node produces the beat-to-beat heart rate oscillations - heart rate variability (HRV). However, this cardiac control system has many features of a nonlinear dynamical system: reciprocally interconnected components and many positive/negative feedback interactions resulting in healthy and adaptive complexity of heart rate dynamics (Thayer and Lane 2000, Friedman 2007). Importantly, a loss of HRV complexity - as a general feature of pathological dynamics indicating maladaptive conditions - is associated with higher risk of cardiovascular adverse outcomes (Goldberger et al. 2002, Bornas et al. 2006, Bär et al. 2007). Taken together, the HRV analysis should represent a noninvasive window into complex cardiac chronotropic regulation providing important information about central-peripheral interaction (Tonhajzerova et al. 2012b).

Recently, nonlinear methods measuring qualitative characteristic of the cardiac time series, such as heart rate asymmetry (HRA), have been shown to be more suitable for a detailed description of heart rate autonomic control system (Javorka et al. 2009, Porta et al. 2009, Tonhajzerova et al. 2012a). Heart rate asymmetry is a physiological phenomenon based on the irreversible dynamics of the heart rate increments and decrements from one beat to another - HRV asymmetry originating from different structure of runs of decelerations and accelerations (Piskorski and Guzik 2011a). The analysis of time asymmetry - as the phenomenon specific for nonequilibrium systems (Hou et al. 2010) - checks the invariance of the statistical properties of a time series after time reversal potentially detecting a qualitative feature of cardiac complex autonomic regulation (Porta et al. 2008). In other words, time irreversibility analysis is capable to detect a specific class of heart rate nonlinear dynamics characterized by a temporal asymmetry (Porta et al. 2008) and the presence of time irreversibility in the heart rate variability results from the complexity of cardiac autonomic control in healthy conditions (Costa et al. 2008). Although analysis of the heart rate asymmetry has been applied to heart rate time series analysis in healthy young subjects during physical stressors - passive and active orthostasis (Casali et al. 2008, De La Cruz Torres and Naranjo Orellana 2010) and in the diseases such as chronic heart failure, postinfarction patients, diabetes mellitus type 1 or depression (Baumert et al. 2009, Porta et al. 2009, Guzik et al. 2010, 2012, Tonhajzerova et al. 2012a), there are not previous studies related to the heart rate time irreversibility in mental disorders from externalizing spectrum such as attention deficit/hyperactivity disorder without comorbidity.

Therefore, we addressed the hypothesis that heart rate time asymmetry as a qualitative feature of heart rate nonlinear dynamics could provide new important information about potential neurocardiac control impairment in ADHD. To the best of our knowledge, it is the first study to use heart rate time irreversibility analysis in children suffering from ADHD without comorbidities and prior pharmacotherapy.

\section{Methods}

The study was approved by the Ethics Committee of Jessenius Faculty of Medicine in Martin, Comenius University in Bratislava in accordance with the Declaration of Helsinki (2000) of the World Medical 
Association. All children/patients/guardians were carefully instructed about the study protocol and they gave informed written consent to participate in the study prior to examination.

\section{Subjects}

We have examined 20 children diagnosed with ADHD at the age 8-12 years (average age: $10.0 \pm 0.3$ years; BMI: $16.4 \pm 0.3 \mathrm{~kg} / \mathrm{m}^{2}$ ) and 20 healthy children matched to age, body mass index and education level (average age: $10.5 \pm 0.4$ years; BMI: $17.1 \pm 0.4 \mathrm{~kg} / \mathrm{m}^{2}$ ). Basic groups` characteristics are presented in Table 1 .

Table 1. The characteristics of ADHD patients and control group.

\begin{tabular}{lrc}
\hline & ADHD $(\mathbf{n}=\mathbf{2 0})$ & Controls $(\mathbf{n = 2 0})$ \\
\hline Age (years) & $10.0 \pm 0.3$ & $10.5 \pm 0.4$ \\
SBP $(\mathrm{mm} \mathrm{Hg})$ & $107 \pm 1.3$ & $108 \pm 1.2$ \\
$D B P(\mathrm{~mm} \mathrm{Hg})$ & $62 \pm 1.2$ & $61 \pm 1.1$ \\
$B M I\left(\mathrm{~kg} / \mathrm{m}^{2}\right)$ & $16.4 \pm 0.3$ & $17.1 \pm 0.4$ \\
\hline
\end{tabular}

Values are expressed as mean \pm SEM, nonsignificant differences were in these parameters. SBP - systolic blood pressure, DBP diastolic blood pressure, BMI - body mass index

Following inclusion criteria were used during enrolling the patients for ADHD group. The ADHD diagnosis - combined type, severe degree of the ADHD, without any comorbidity - was ascertained by two independent specialists - child and adolescent psychiatrists according to Diagnostic and Statistical Manual of Mental Disorders, Fourth Edition, Text Revision (DSM-IV-TR; American Psychiatric Association 2000). Consequently, the ADHD patients were ascertained not to have other psychiatric diagnoses (e.g. conduct disorders) according to diagnostic criteria of DSM-IV-TR by two independent child/adolescent psychiatrists. After this initial procedure, the ADHD diagnosis and absence of any symptoms of other psychiatric diagnoses in our studied sample were confirmed by supervised qualified specialist in child and adolescent psychiatry prior to inclusion in this study. Additionally, only the patients that have never received any treatment prior to the study were included in this study, and the HRV examination was performed prior to planned treatment by atomoxetine or methylphenidate.

For controls, the control group was recruited from healthy children of primary school with respect to age, body mass index, education level and physical activity. Similarly, control participants did not take any medication or substances influencing cardiovascular system. Furthermore, the control participants have been never treated for any mental disorder. Importantly, only boys were recruited into the study because of the gender as one of the physiological factors influencing the HRV (Tonhajzerova et al. 2002).

Following strict exclusion criteria were used for both groups (ADHD patients and controls): no evidence/history of cardiovascular, respiratory, endocrinological, neurological, infectious or other disorders/factors known to affect HRV (including obesity, overweight, underweight, alcohol/drug abuse, intensive regular physical training). Moreover, smokers were excluded from this study.

\section{Procedure}

All subjects were examined in the morning between 8.00 and 12.00 a.m. after a normal breakfast in quiet room with standard conditions (temperature, minimalisation of stimuli). After $10 \mathrm{~min}$ of rest and stabilization of the heart rate (for an exclusion of possible stress effect), the continuous recording of the R-R intervals in a supine position followed by orthostatic stress (change of posture from lying to standing) was performed using VarCor PF6 (Dimea, Czech Republic) with sampling frequency of $1000 \mathrm{~Hz}$. The time spent in each interval was $5 \mathrm{~min}$.

\section{The heart rate asymmetry analysis}

The segments of 300 RR intervals without artefacts were analyzed between the first and the fifth minute of the supine position and in response to physiological stimulus $\left(1^{\text {st }}-5^{\text {th }} \min\right.$ of standing). Following indices suitable for short-term heart rate recordings were used to measure the time irreversibility of HRV series:

1. Porta's index P\% (Porta et al. 2008) is based on the evaluation of the percentage of negative $\Delta R R$ with respect to the total number of $\Delta R R \neq 0$;

$$
P \%=\frac{N\left(\Delta d^{-}\right)}{N(\Delta d \neq 0)} 100
$$

2. Guzik's index G\% (Guzik et al. 2006) is based on the evaluation of the percentage of the cumulative square values of positive $\Delta R R$ to the cumulative square of all $\Delta$ RRs. Contrary to $\mathrm{P} \%$, the calculation of Guzik's index $(G \%)$ considers also the magnitude of the difference between two RR intervals 


$$
G \%=\frac{\sum_{i=1}^{N\left(\Delta d^{+}\right)} \Delta d(i)^{+2}}{\sum_{i=1}^{N(\Delta d)} \Delta d(i)^{2}} 100
$$

The range of $P \%$ and $G \%$ indexes is from 0 to 100. The number 50 represents a "cut-off point" for significant changes in these parameters. $\mathrm{P} \%$ higher than 50 means that the negative changes $\left(\Delta d^{-}\right)$are larger than the positive $\left(\Delta d^{+}\right)$(i.e. bradycardic runs are shorter than tachycardic ones). G\% higher than 50 means that the average magnitude $\left|\Delta d^{+}\right|$is larger than negative one. The values below the 50 evoke the opposite reactions.

3. Ehlers' index (Ehlers et al. 1998) is based on the evaluation of the skewness of the distribution of $\triangle R R$

$$
E=\frac{\sum_{i=1}^{N(\Delta d)} \Delta d(i)^{3}}{\left\{\sum_{i=1}^{N(\Delta d)} \Delta d(i)^{2}\right\}^{3 / 2}}
$$

The limiting value of this index represents number 0 . Ehlers' index, higher than 0 , indicates, that the distribution of $\Delta d$ is skewed toward positive values and vice versa.

The nonlinear HRV parameters show the adequate reproducibility, which underlines their suitability for the application (La Fountaine et al. 2010). In addition, mean RR interval (ms) - as a reciprocal value of heart rate - was calculated.

\section{Statistical analysis}

Statistical analysis was performed using the statistical software package SYSTAT 10 for Windows (SSI, Richmond, CA, USA). The non-gaussian/gaussian distribution was ascertained by Lilliefors test. Two-way ANOVA with one repeated measures factor (,position“: supine vs. standing) and one grouping factor (,group“: ADHD or control) was used for data analysis with gaussian distribution (all parameters). Post-hoc univariate $\mathrm{F}$ test was used for between-groups comparison. The probabilities $\mathrm{p}<0.05$ were considered as significant. All the data are expressed as mean \pm SEM.

\section{Results}

Between groups comparison for time irreversibility indices

ANOVA revealed a significant difference between groups in time irreversibility indices $\mathrm{P} \%$ and $\mathrm{G} \%$ ( $\mathrm{F}=10.972, \mathrm{p}=0.002 ; \mathrm{F}=13.354, \mathrm{p}=0.001$, respectively), and in the mean $R R$ interval $(F=8.427, p=0.006)$.

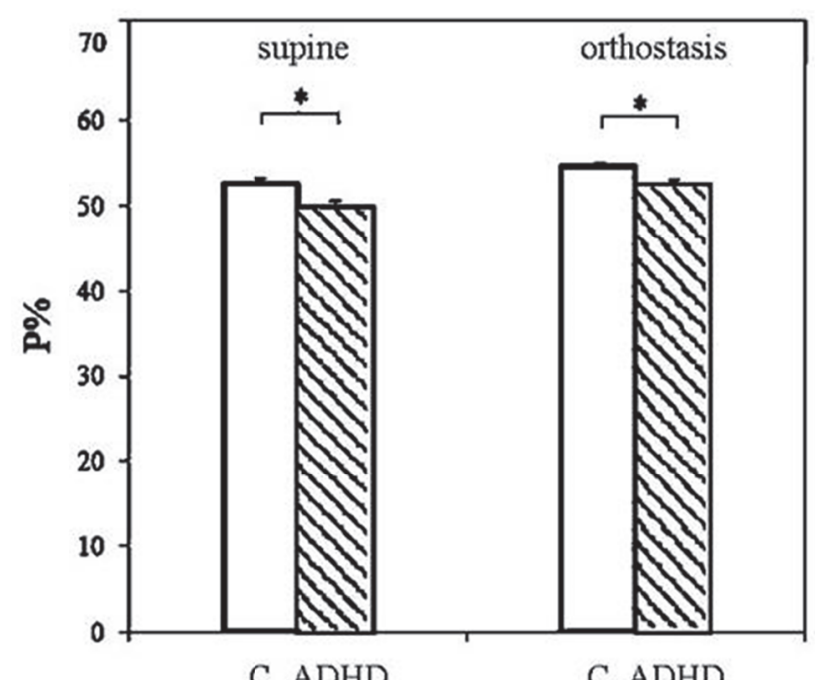

Fig. 1. Mean values of Porta index (P\%) in a supine position and during orthostasis. C - controls, ADHD - attention deficit/hyperactivity disorder. $* \mathrm{p}<0.05$

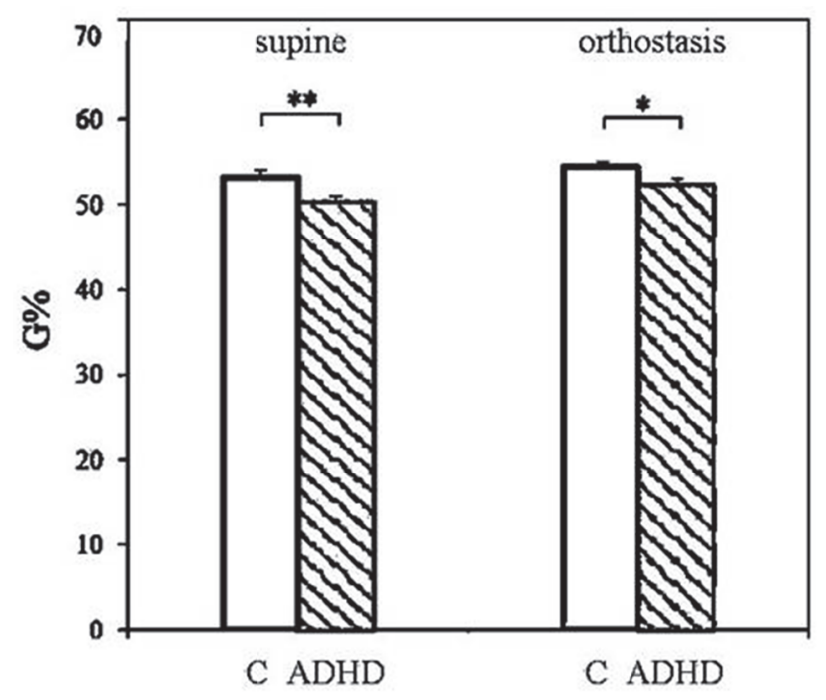

Fig. 2. Mean values of Guzik index (G\%) in a supine position and during orthostasis. $\mathrm{C}-$ controls, ADHD - attention deficit/hyperactivity disorder. $* \mathrm{p}<0.05, * * \mathrm{p}<0.01$

\section{The effect of body position on time irreversibility indices}

ANOVA revealed significant effect of repeated measures factor of ,position“ (lying to standing orthostatic test) for time irreversibility indices: $\mathrm{P} \%$ $(\mathrm{F}=12.477, \mathrm{p}=0.001), \mathrm{G} \%(\mathrm{~F}=5.584, \mathrm{p}=0.023)$, and $\mathrm{E}$ $(\mathrm{F}=8.053, \mathrm{p}=0.007)$, and for mean $\mathrm{RR}$ interval $(\mathrm{F}=202.156, \quad \mathrm{p}=0.001)$. No significant interactions between two factors (,position“ $\mathrm{x}$,group“) were found for all the parameters $(\mathrm{P} \%, \mathrm{G} \%, \mathrm{E}, \mathrm{RR}$ interval).

\section{Post hoc analysis}

Post hoc tests revealed that both time irreversibility indices $(\mathrm{P} \%, \mathrm{G} \%)$ were significantly 
reduced in the ADHD compared to controls in a supine position $\quad(F=6.387, \quad p=0.016 ; \quad F=7.613, \quad p=0.009$, respectively; Fig. 1,2). Similarly, the orthostatic load showed significantly lower heart rate asymmetry parameters $\mathrm{P} \%, \quad \mathrm{G} \% \quad(\mathrm{~F}=5.672, \quad \mathrm{p}=0.022 ; \mathrm{F}=5.869$, $\mathrm{p}=0.020$, respectively; Fig. 1,2) in ADHD group compared to controls. No significant differences between ADHD and controls were found for Ehlers' index (E) in both positions - lying and standing $(\mathrm{F}=3.149, \mathrm{p}=0.084$; $\mathrm{F}=1.764, \mathrm{p}=0.192$, respectively). Additionally, post hoc analysis showed that mean RR interval was significantly shortened in the ADHD compared to controls in both positions - supine $(683 \pm 21 \mathrm{~ms}$ vs. $759 \pm 20 \mathrm{~ms} ; \mathrm{F}=5.770$, $\mathrm{p}=0.021)$ and during orthostasis $(534 \pm 15 \mathrm{~ms}$ vs. $605 \pm 16 \mathrm{~ms} ; \mathrm{F}=9.522, \mathrm{p}=0.004)$.

\section{Discussion}

This study examined heart rate asymmetry (HRA) as a qualitative feature of heart rate complex dynamics in children suffering from ADHD at rest and in response to physiological stress (orthostasis). Our hypothesis was confirmed. This studied group consisting of untreated children suffering from ADHD without comorbidity demonstrated reduced indices of heart rate time irreversibility ( $\mathrm{P} \%, \mathrm{G} \%)$ under resting conditions, and in response to change of posture from lying to standing - orthostatic load associated with tachycardia. These findings could indicate an abnormal complex cardiac functioning in pure ADHD children.

Heart rate asymmetry is related to nonlinear behavior of cardiac function, which is manifested by the most complex central-peripheral interrelationships resulting in the presence of asymmetric patterns (i.e. waveforms characterized by the upward side shorter or longer than the downward side) (Porta et al. 2008). It is reported to be the highest for healthy physiological systems under resting conditions (Costa et al. 2005) and to decrease with pathology, thus providing a marker for any loss of normal functionality (Karmakar et al. 2010, 2012). Recent studies suggest that heart rate asymmetric pattern in healthy subjects is characterized by bradycardic runs shorter than tachycardic ones (i.e. the heart rate decelerates more rapidly than it accelerates) indexed by values of $\mathrm{P} \%$ and $\mathrm{G} \%$ indices larger than 50 (Porta et al. 2008, 2009). Interestingly, other authors used the redefined Guzik's index value of symmetry equal to 50 (Karmakar et al. 2010). We found significantly reduced heart rate time asymmetry indices $(\mathrm{G} \%, \mathrm{P} \%)$ in children with ADHD compared to controls in a supine position, and these values were closer to 50 indicating heart rate symmetric pattern in the ADHD group.

Nevertheless, the physiological mechanisms responsible for heart rate irreversibility are unclear. Importantly, the heart rate asymmetry (i.e. heart rate accelerations and decelerations indexed by $\mathrm{P} \%, \mathrm{G} \%$ and E) are influenced by the dynamic sympathovagal balance: heart rate accelerations can be caused by the increased sympathetic regulatory inputs, reduced parasympathetic drive or be an effect of both. Similarly, heart rate decelerations can be caused by a reduction in sympathetic activity, augmentation of parasympathetic tone or both altered nervous systems (Piskorski and Guzik 2011b). Further, Karmakar et al. (2012) showed that pharmacological autonomic modulation by atropine (parasympathetic blockade) or scopolamine (parasympathetic agitation) changes the expression of heart rate asymmetry in the following pattern: atropine reduces time irreversibility and scopolamine increases its expression. Taken together, it seems that heart rate irreversibility indices are sensitive to the sympathetic and in particular parasympathetic regulatory mechanisms which in turn modulate the electrical properties of cardiac cells (Porta et al. 2008, Guzik et al. 2013). Therefore, our findings showed the reduced heart rate time asymmetry in children suffering from ADHD compared to controls indicating an impairment of cardiac autonomic complex control in a supine position, in which the cardiac vagal activity is dominant.

Orthostatic test - the change of posture from supine to the standing position - is a well-known physiological maneuver characterized by a shifted balance of the autonomic nervous system towards progressive increase of the sympathetic activity and a concomitant decrease in the vagal activity. It is important to note that neurocardiac reactivity induced by orthostatic test is associated with autonomic regulatory subcortical centres (hypothalamus, brainstem), and at the level of the peripheral organ - heart. From this point of view, it can be used as an ideal "model" to study the complex dynamics of activated heart rate autonomic regulatory inputs. Importantly, recent studies suggest that time irreversibility indices (Porta's, Guzik's index) are sensitive to the increase in the sympathetic modulation produced by head-up tilt test (Porta et al. 2008) or active orthostasis in healthy subjects (Chladekova et al. 2011). Our findings showed the decreased heart rate asymmetry indices induced by orthostatic load indicating potential 
discrete abnormalities in neurocardiac complex regulatory mechanisms in ADHD children compared to control group. Therefore, it is assumed that children with ADHD have a lower functional reserve capacity and must work harder and expend a greater portion of their autonomic reserve in order to regulate minor pertubations (Rash and Aguirre-Camacho 2012). Importantly, baroreflex sensitivity is different for blood pressure increases and reductions; thus, heart rate asymmetry could be to some extent attributed to the baroreflex characteristics (Piskorski and Guzik 2011a). From this point of view, we can speculate that baroreflex function as a principal mechanism in cardiovascular adaptive response to posture change from lying to standing - is impaired in ADHD children. Further research based on baroreflex analysis with continuous blood pressure recording and subsequent baroreflex sensitivity is needed.

It seems that time irreversibility parameters could provide important information about complex neurocardiac control dynamics in pure ADHD, but the mechanisms involved in heart rate asymmetry are unclear and still discussed. The short-term HRV is influenced by dominant cardiac parasympathetic-linked regulatory mechanism - respiratory sinus arrhythmia (RSA) that is characterized by heart rate oscillations related to breathing pattern (heart rate increases during inspiration and decreases during expiration). It is important to note that this coupling of heart rate oscillations to the respiratory cycle can be affected by an asymmetric pattern of single breathing cycle, i.e. inspiration and expiration times are not equal and expiratory phase lasts longer in a healthy human. Thus, the RSA is considered as an important physiological mechanism contributing to the heart rate asymmetry (Piskorski and Guzik 2011a). Our previous study revealed reduced baseline cardiac vagal regulation quantified by spectral analysis of the heart rate variability at the respiratory-related highfrequency band (HF-HRV as an index of RSA) in ADHD associated with greater percentual decrease in vagal withdrawal in response to orthostatic test indicating potential subclinical abnormal dynamic activation of the autonomic nervous system in response to posture change in children with attention deficit/hyperactivity disorder (Tonhajzerova et al. 2009). These results are in agreement with other studies which found reduced RSA amplitude indicating cardiac vagal dysfunction in ADHD (Beauchaine 2001, Crowell et al. 2006, Buchhorn et al. 2012). According to the polyvagal theory (Porges 1995, 2009), RSA is considered as a noninvasive index of cardiac vagal modulation as well as emotional regulation, and the ADHD is associated with emotional dysregulation (Musser et al. 2013). From this perspective, a potential connection between ADHD-linked emotional dysregulation (i.e. emotional lability due to emotional immaturity) and reduced cardiovagal function might represent the possible mechanisms leading to the altered heart rate asymmetry observed in our sample of child patients suffering from ADHD.

Generally, the neurophysiological mechanisms leading to heart rate asymmetry impairment as a qualitative feature of nonlinear dynamics in the complex cardiac autonomic control system related to ADHD are still unexplored. Recent neuroimaging studies suggest the involvement of developmentally abnormal brain regions including prefrontal cortex in ADHD (Cortese 2012). Consequently, the importance of the inhibitory processes by prefrontal cortex related to heart rate complex control as a sign of health was emphasized by some research groups (Friedman 2007, Thayer and Lane 2000). The central autonomic network, characterized by the reciprocally interconnected neural structures, allows the prefrontal cortex to exert an inhibitory influence on subcortical structures associated with defensive behavior and thus allows the organism to flexibly regulate its behavior in response to changing environmental demands (Thayer 2006). For example, the amygdala, which has outputs to autonomic as well as other regulatory systems, and becomes active during threat/uncertainty, is under tonic inhibitory control from the prefrontal cortex. Thus, under conditions of the threat, the prefrontal cortex becomes hypoactive which is associated with disinhibition of sympathoexcitatory circuits involved in the cardiac autonomic regulation. Importantly, proper functioning of inhibitory processes is vital to the preservation of the integrity of the system and therefore is vital to health (Tonhajzerova et al. 2012b).

In ADHD children, the deficit in prefrontal functioning connected to limbic system and consequent alteration of baroreflex function as well as the modifications in a network of brain regions (e.g. anterior cingulate cortex) are supposed (Börger et al. 1999, Pliszka et al. 2006). In the molecular aspect, the prefrontal cortex is powerfully modulated by catecholamines, in particular norepinephrine and dopamine, which are thought to be involved in the regulation of processes such as selective attention or arousal state (Gamo and Arnsten 2011). From this context, ADHD was found to be associated with a wide 
variety (up to 158 genes) of genetic abnormalities of dopaminergic, noradrenergic, and also serotoninergic transmission (receptors, transporters, pathway modulators, enzymes of the synthesis and degradation and regulators of the neurotransmitters' release) (Cristino et al. 2014, Lesch 2009). Specifically, the mutation of alpha2A-adrenoreceptor gene (ADRA2A) was found to impair the cognitive functions of prefrontal cortex (Franowicz et al. 2002), and a significant association of the $3081(\mathrm{~A} / \mathrm{T})$ polymorphism in the norepinephrine transporter (NET) gene with ADHD development was identified (Kim et al. 2006). Moreover, both NET -3081(A/T) and ADRA2A MspI polymorphisms were found to be associated with cardiovascular side effects of methylphenidate treatment in children suffering from ADHD (Cho et al. 2012). Therefore, the genetically mediated abnormalities in the neurotransmission could contribute to the discrete dysfunctions in the prefrontal cortex, limbic system, locus coeruleus-noradrenergic system and other related brain structures that are also included in the neurocardiac complex regulation (Samuels and Szabadi 2008a,b).

Furthermore, the deficits of prefrontal cortex with respect to structural and functional neuroimaging, dopaminergic and noradrenergic dysregulation are associated with a loss of inhibitory processes critical for adaptive heart rate neural regulation. Interestingly, the posterior transection of the medial prefrontal cortex significantly increased the stress-induced catecholamines release in animal model suggesting thus an inhibitory effect of prefrontal cortex on the sympathoadrenal activity (Ondicova et al. 2012). It seems that the prefrontal cortex dysfunction could represent one of the underlying mechanisms of the impaired catecholaminergic regulation. For example, Dvorakova et al. (2007) found increased urinary levels of both catecholamines (norepinephrine, epinephrine) in ADHD children, and the norepinephrine concentrations significantly correlated with the degree of hyperactivity. Other studies demonstrated the lower ratios of urinary norepinephrine to normetanephrine, and epinephrine to metanephrine after mental tasks associated with higher resting catecholamine levels indicating peripheral catecholaminergic dysregulation characterized by a potential tonic sympathoadrenal overactivation associated with maladaptive catecholamine stress reactivity in ADHD (Konrad et al. 2003, Pliszka et al. 1994). Moreover, ADHD seems to be also associated with dysregulation in other allostatic systems, such as hypothalamic-pituitary-adrenocortical axis activity resulting in the lower resting and stressful cortisol levels in ADHD, as noted in recent studies (Ma et al. 2011, Pesonen et al. 2011). Taken together, we suggest that the potential pathomechanisms leading to the impairment of heart rate asymmetric pattern in untreated ADHD children are complex, and the alterations in heart rate irreversibility might identify potential subtle abnormalities in neurocardiac regulatory mechanisms indicating an important step towards heart-brain understanding in pure ADHD.

It should be noted that deficient cardiovascular stress reactivity was also found in adult treatment-free ADHD, and thus the impaired complex cardiac autonomic control could represent a risk factor for later cardiovascular adverse complications, such as tachycardia or hypertensive reaction observable in adult ADHD-treated patients (Hammerness et al. 2011, Hirvikoski et al. 2011). We suggest that the assessment of early and subclinical abnormal signs of complex neurocardiac regulation could represent an important contribution in clinical practice, e.g. in the cardiac function monitoring during psychopharmacological treatment.

\section{Study limitations}

This study included a homogeneous group of male patients with ADHD - combined type without any comorbidity and severe degree of the ADHD. However, the assessment of the interaction between heart rate asymmetry indices and other ADHD subtypes (predominantly inattentive type, and predominantly hyperactive/impulsive type) as well as the ADHD features/severity assessed from different rating scales could have given important information. Further research in this field is needed.

Additionally, several studies hypothesize that distinct core neurobiological deficits may underlie the developmental course of ADHD in males and females (Hermens et al. 2005). From this perspective, we suggest that gender could affect the heart rate asymmetry parameters in ADHD, and thus our results may only be representative for male ADHD patients. Therefore, the potentially important ADHD-linked gender differences in the heart rate asymmetry need to be identified in future studies.

\section{Conclusion}

Our study is the first to report the altered heart rate asymmetric pattern in ADHD children at rest as well 
as in response to posture change from lying to standing (orthostasis). These findings might reflect a deficiency in complex cardiac regulatory system as a potential pathomechanism leading to later cardiac adverse outcomes. It seems that HRV nonlinear analysis based on heart rate irreversibility could represent a new indicator to illuminate the pathway linking complex neurocardiac integrity and attention deficit/hyperactivity disorder in untreated children without comorbidity.

\section{Conflict of Interest}

There is no conflict of interest.

\section{Acknowledgements}

This study was supported by VEGA 1/0087/14, VEGA 1/0223/12, APVV 0235/12.

\section{References}

AMERICAN PSYCHIATRIC ASSOCIATION: Diagnostic \& Statistical Manual of Mental Disorder DSM IV-TR (Text Revision), $4^{\text {th }}$ ed. American Psychiatric Association, Washington, D.C., 2000, 943 pp.

BAUMERT M, LAMBERT GW, DAWOOD T, LAMBERT EA, ESLER MD, MCGRANE M, BARTON D, SANDERS P, NALIVAIKO E: Short-term heart rate variability and cardiac norepinephrine spillover in patients with depression and panic disorder. Am J Physiol 297: H674-H679, 2009.

BÄR KJ, BOETTGER MK, KOSCHKE M, SCHULZ S, CHOKKA P, YERAGANI VK, VOSS A: Non-linear complexity measures of heart rate variability in acute schizophrenia. Clin Neurophysiol 118: 2009-2015, 2007.

BEAUCHAINE T: Vagal tone, development, and Gray's motivational theory: toward an integrated model of autonomic nervous system functioning in psychopathology. Dev Psychopathol 13: 183-214, 2001.

BEAUCHAINE TP, GATZKE-KOPP L, MEAD HK: Polyvagal Theory and developmental psychopathology: emotion dysregulation and conduct problems from preschool to adolescence. Biol Psychol 74: 174-184, 2007.

BEAUCHAINE TP, GATZKE-KOPP L, NEUHAUS E, CHIPMAN J, REID MJ, WEBSTER-STRATTON C: Sympathetic- and parasympathetic-linked cardiac function and prediction of externalizing behavior, emotion regulation, and prosocial behavior among preschoolers treated for ADHD. J Consult Clin Psychol 81: 481-93, 2013.

BENARROCH EE: The central autonomic network: functional organization, dysfunction, and perspective. Mayo Clinic Proc 68: 988-1001, 1993.

BORNAS X, LLABRES J, NOGUERA M, LOPEZ AM, GELABERT JM, VILA I: Fear induced complexity loss in the electrocardiogram of flight phobics: a multiscale entropy analysis. Biol Psychol 73: 272-279, 2006.

BÖRGER N, VAN DER MEERE J, RONNER A, ALBERTS E, GEUZE R, BOGTE H: Heart rate variability and sustained attention in ADHD children - attention deficit-hyperactivity disorder. J Abnorm Child Psychol 27: 25-33, 1999.

BUCHHORN R, CONZELMANN A, WILLASCHEK C, STORK D, TAURINES R, RENNER T: Heart rate variability and methylphenidate in children with ADHD. ADHD Atten Defic Hyperact Disord 4: 85-91, 2012.

CASALI KR, CASALI AG, MONTANO N, IRIGOYEN MC, MACAGNAN F, GUZETTI S, PORTA A: Multiple testing strategy for the detection of temporal irreversibility in stationary time series. Phys Rev E Stat Nonlin Soft Matter Phys 77: 066204, 2008.

CHLADEKOVA L, CZIPPELOVA B, TURIANIKOVA Z, TONHAJZEROVA I, CALKOVSKA A, BAUMERT M, JAVORKA M: Multiscale time irreversibility of heart rate and blood pressure variability during orthostasis. Physiol Meas 33: 1747-1756, 2011.

CHO SC, KIM BN, CUMMINS TD, KIM JW, BELLGROVE MA: Norepinephrine transporter -3081(A/T) and alpha2A-adrenergic receptor MspI polymorphisms are associated with cardiovascular side effects of OROSmethylphenidate treatment. J Psychopharmacol 26: 380-389, 2012.

CORTESE S: The neurobiology and genetics of Attention-Deficit/Hyperactivity Disorder (ADHD): what every clinician should know. Eur J Paediatr Neurol 16: 422-433, 2012.

COSTA M, GOLDBERGER AL, PENG CK: Multiscale entropy analysis of biological signals. Phys Rev E Stat Nonlin Soft Matter Phys 71: 021906, 2005. 
COSTA MD, PENG CK, GOLDBERGER AL: Multiscale analysis of heart rate dynamics: entropy and time irreversibility measures. Cardiovasc Eng 8: 88-93, 2008.

CRISTINO AS, WILLIAMS SM, HAWI Z, AN JY, BELLGROVE MA, SCHWARTZ CE, COSTA LDA F, CLAUDIANOS C: Neurodevelopmental and neuropsychiatric disorders represent an interconnected molecular system. Mol Psychiatry 19: 294-301, 2014.

CROWELL SE, BEAUCHAINE TP, GATZKE-KOPP L, SYLVERS P, MEAD H, CHIPMAN-CHACON J: Autonomic correlates of attention-deficit/hyperactivity disorder and oppositional defiant disorder in preschool children. J Abnorm Psychol 115: 174-178, 2006.

DE LA CRUZ TORRES B, NARANJO ORELLANA J: Multiscale time irreversibility of heartbeat at rest and during aerobic exercise. Cardiovasc Eng 10: 1-4, 2010.

DVORAKOVA M, JEZOVA D, BLAZICEK P, TREBATICKA J, SKODACEK I, SUBA J, WACZULIKOVA I, ROHDEWALD P, DURACKOVA Z: Urinary catecholamines in children with attention deficit hyperactivity disorder (ADHD): modulation by a polyphenolic extract from pine bark (pycnogenol). Nutr Neurosci 10: 151$157,2007$.

EHLERS CL, HAVSTAD J, PRICHARD D, THEILER J: Low doses of ethanol reduce evidence for nonlinear structure in brain activity. $J$ Neurosci 18: 7474-7486, 1998.

FRANOWICZ JS, KESSLER LE, BORJA CM, KOBILKA BK, LIMBIRD LE, ARNSTEN AF: Mutation of the alpha2A-adrenoceptor impairs working memory performance and annuls cognitive enhancement by guanfacine. J Neurosci 22: 8771-8777, 2002.

FRIEDMAN BH: An autonomic flexibility-neurovisceral integration model of anxiety and cardiac vagal tone. Biol Psychol 74: 185-199, 2007.

FURMAN L: What is Attention-Deficit Hyperactivity Disorder (ADHD)? J Child Neurol 20: 994-1002, 2005.

GAMO NJ, ARNSTEN AFT: Molecular modulation of prefrontal cortex: rational development of treatment for psychiatric disorders. Behav Neurosci 125: 282-296, 2011.

GOLDBERGER AL, PENG CK, LIPSITZ LA: What is physiologic complexity and how does it change with aging and disease? Neurobiol Aging 23: 23-26, 2002.

GUZIK P, PISKORSKI J, KRAUZE T, WYKRETOWICZ A, WYSOCKI H: Heart rate asymmetry by Poincaré plots of RR intervals. Biomed Tech (Berl) 51: 272-275, 2006.

GUZIK P, PISKORSKI J, KRAUZE T, WYKRETOWICZ A, WYSOCKI H: Partitioning total heart rate variability. Int J Cardiol 144: 138-139, 2010.

GUZIK P, PISKORSKI J, BARTHEL P, BAUER A, MÜLLER A, JUNK N, ULM K, MALIK M, SCHMIDT G: Heart rate deceleration runs for postinfarction risk prediction. J Electrocardiol 45: 70-76, 2012.

GUZIK P, ZUCHOWSKI B, BLASZYK K, SENIUK W, WASNIEWSKI M, GWIZDALA A, WYKRETOWICZ A, PISKORSKI J: Asymmetry of the variability of heart rate and conduction time between atria and ventricles. Circ J 77: 2904-2911, 2013.

HAMMERNESS PG, SURMAN CBH, CHILTON A: Adult attention-deficit/hyperactivity disorder treatment and cardiovascular implications. Curr Psychiatry Rep 13: 357-363, 2011.

HERMENS DF, KOHN MR, CLARKE SD, GORDON E, WILLIAMS LM: Sex differences in adolescent ADHD: findings from concurrent EEG and EDA. Clin Neurophysiol 116: 1455-1463, 2005.

HIRVIKOSKI T, OLSSON EMG, NORDENSTRÖM A, LINDHOLM T, NORDENSTRÖM AL, LAJIC S: Deficient cardiovascular stress reactivity predicts poor executive functions in adults with attention-deficit/hyperactivity disorder. J Clin Exp Neuropsychol 33: 63-73, 2011.

HOU F, ZHUANG J, BIAN C, TONG T, CHEN Y, YIN J, QIU X, NING X: Analysis of heartbeat asymmetry based on multi-scale time irreversibility test. Physica A 389: 754-760, 2010.

IMERAJ L, ANTROP I, ROEYERS H, DESCHEPPER E, BAL S, DEBOUTTE D: Diurnal variations in arousal: a naturalistic heart rate study in children with ADHD. Eur Child Adolesc Psychiatry 20: 381-392, 2011.

JAVORKA M, TURIANIKOVA Z, TONHAJZEROVA I, JAVORKA K, BAUMERT M: The effects of orthostasis on recurrence quantification analysis of heart rate and blood pressure dynamics. Physiol Meas 30: 29-41, 2009.

KARMAKAR CH, KHANDOKER A, PALANISWAMI M: Heart rate asymmetry in altered parasympathetic nervous system activity. Comp Cardiol 37: 601-604, 2010. 
KARMAKAR CH, KHANDOKER A, PALANISWAMI M: Investigating the changes in heart rate asymmetry (HRA) with pertubation of parasympathetic nervous system. Australas Phys Eng Sci Med 35: 465-474, 2012.

KIM CH, HAHN MK, JOUNG Y, ANDERSON SL, STEELE AH, MAZEI-ROBINSON MS, GIZER I, TEICHER MH, COHEN BM, ROBERTSON D, WALDMAN ID, BLAKELY RD, KIM KS: A polymorphism in the norepinephrine transporter gene alters promoter activity and is associated with attention-deficit hyperactivity disorder. Proc Natl Acad Sci USA 103: 19164-19169, 2006.

KONRAD K, GAUGGEL S, SCHUREK J: Catecholamine functioning in children with traumatic brain injuries and children with attention-deficit/hyperactivity disorder. Brain Res Cogn Brain Res 16: 425-433, 2003.

LA FOUNTAINE MF, WECHT JM, SPUNGEN AM, BAUMAN WA: Intra-inter visit reproducibility of short-term linear and nonlinear measurement of heart rate variability in tetraplegia and neurologically intact controls Physiol Meas 31: 363-374, 2010.

LESCH KP: Attention-Deficit/Hyperactivity Disorder. In: Encyclopedia of Molecular Mechanisms of Disease. LANG F (ed.), Springer-Verlag, Berlin Heidelberg, 2009, pp 188-191.

MA L, CHEN YH, CHEN H, LIU YY, WANG YX: The function of hypothalamus - pituitary - adrenal axis in children with ADHD. Brain Res 1368: 159-162, 2011.

MUSSER ED, GALLOWAY-LONG HS, FRICK PJ, NIGG JT: Emotion regulation and heterogeneity in attention deficit/hyperactivity disorder. J Am Acad Child Adolesc Psychiatry 52: 163-171, 2013.

ONDICOVA K, KVETNANSKY R, MRAVEC B: Medial prefrontal cortex transection enhanced stress-induced activation of sympathoadrenal system in rats. Endocr Regul 46: 129-136, 2012.

PESONEN AK, KAJANTIE E, JONES A, PYHÄLÄ R, LAHTI J, HEINONEN K, ERIKSSON JG, STRANDBERG TE, RÄIKKÖNEN K: Symptoms of attention deficit hyperactivity disorder in children are associated with cortisol responses to psychosocial stress but not with daily cortisol levels. J Psychiatr Res 45: 1471-1476, 2011.

PISKORSKI J, GUZIK P: Asymmetric properties of long-term and total heart rate variability. Med Biol Eng Comput 49: 1289-1297, 2011a.

PISKORSKI J, GUZIK P: The structure of heart rate asymmetry: deceleration and acceleration runs. Physiol Meas 32: 1011-1023, $2011 \mathrm{~b}$.

PLISZKA SR, MAAS JW, JAVORS MA, ROGENESS GA, BAKER J: Urinary catecholamines in attention-deficit hyperactivity disorder with and without comorbid anxiety. $J$ Am Acad Child Adolesc Psychiatry 33: 11651173, 1994.

PLISZKA SR, GLAHN DC, SEMRUD-CLIKEMAN M, FRANKLIN C, PEREZ R, XIONG J, LIOTTI M: Neuroimaging of inhibitory control areas in children with attention deficit hyperactivity disorder who were treatment naive or in long-term treatment. Am J Psychiatry 163: 1052-1060, 2006.

PORGES SW: Orienting in a defensive world: mammalian modification of our evolutionary heritage. A polyvagal theory. Psychophysiology 32: 301-318, 1995.

PORGES SW: The polyvagal perspective. Biol Psychol 74: 116-143, 2007.

PORGES SW: The polyvagal theory: new insights into adaptive reactions of the autonomic nervous system. Clev Clin J Med 76 (Suppl 2): 86-90, 2009.

PORTA A, CASALI KR, CASALI AG, GNECCHI-RUSCONE T, TOBALDINI E, MONTANO N, LANGE S, GEUE D, CYSARZ D, VAN LEEUWEN P: Temporal asymmetries of short-term heart period variability are linked to autonomic regulation. Am J Physiol 295: R550-R557, 2008.

PORTA A, DADDIO G, BASSANI T, MAESTRI R, PINNA GD: Assessment of cardiovascular regulation through irreversibility analysis of heart period variability: a 24 hours Holter study in healthy and chronic heart failure populations. Philos Trans A Math Phys Eng Sci 367: 1359-1375, 2009.

RASH JA, AGUIRRE-CAMACHO A: Attention-deficit hyperactivity disorder and cardiac vagal control: a systematic review. Atten Defic Hyperact Disord 4: 167-177, 2012.

SAMUELS ER, SZABADI E: Functional neuroanatomy of the noradrenergic locus coeruleus: its roles in the regulation of arousal and autonomic function part I: principles of functional organisation. Curr Neuropharmacol 6: 235253, 2008a. 
SAMUELS ER, SZABADI E: Functional neuroanatomy of the noradrenergic locus coeruleus: its roles in the regulation of arousal and autonomic function part II: physiological and pharmacological manipulations and pathological alterations of locus coeruleus activity in humans. Curr Neuropharmacol 6: 254-285, 2008b.

THAYER JF: On the importance of inhibition: central and peripheral manifestations of nonlinear inhibitory processes in neural systems. Dose Response 4: 2-21, 2006.

THAYER JF, LANE RD: A model of neurovisceral integration in emotion regulation and dysregulation. J Affect Disord 61: 201-216, 2000.

THAYER JF, LANE RD: Claude Bernard and the heart-brain connection: further elaboration of a model of neurovisceral integration. Neurosci Biobehav Rev 33: 81-88, 2009.

THAYER JF, STERNBERG E: Beyond heart rate variability: vagal regulation of allostatic systems. Ann N Y Acad Sci 1088: 361-372, 2006.

TONHAJZEROVA I, JAVORKA K, JAVORKA M, PETRASKOVA M: Cardiovascular autonomic nervous system tests: reference values in young people (15-19 years) and influence of age and gender. Clin Physiol 6: 398-403, 2002.

TONHAJZEROVA I, ONDREJKA I, ADAMIK P, HRUBY R, JAVORKA M, TRUNKVALTEROVA Z, MOKRA D, JAVORKA K: Changes in the cardiac autonomic regulation in children with attention deficit hyperactivity disorder (ADHD). Indian J Med Res 130: 44-50, 2009.

TONHAJZEROVA I, ONDREJKA I, CHLADEKOVA L, FARSKY I, VISNOVCOVA Z, CALKOVSKA A, JURKO A, JAVORKA M: Heart rate time irreversibility is impaired in adolescent major depression. Prog Neuropsychopharmacol Biol Psychiatry 39: 212-217, 2012a.

TONHAJZEROVA I, ONDREJKA I, TURIANIKOVA Z, JAVORKA K, CALKOVSKA A, JAVORKA M: Heart rate variability: an index of brain-heart interaction. In: Tachycardia. T. YAMADA (ed.), InTech, Rijeka, Croatia, 2012b, pp 185-202. 